\title{
BMJ Open Gender-specific prevalence of metabolic-associated fatty liver disease among government employees in Tianjin, China: a cross-sectional study
}

\author{
Ya-Ping Huang, ${ }^{1,2}$ Shi Zhang, ${ }^{2}$ Minying Zhang, ${ }^{3}$ Yi Wang, ${ }^{2}$ Wen-Hong Wang, ${ }^{2}$ \\ Jing Li, ${ }^{2}$ Chunjun Li (D) , ${ }^{2}$ Jing-Na Lin²
}

To cite: Huang Y-P, Zhang S, Zhang M, et al. Gender-specific prevalence of metabolicassociated fatty liver disease among government employees in Tianjin, China: a crosssectional study. BMJ Open 2021;11:e056260. doi:10.1136/ bmjopen-2021-056260

- Prepublication history and additional supplemental material for this paper are available online. To view these files, please visit the journal online (http://dx.doi.org/10.1136/ bmjopen-2021-056260).

Received 13 August 2021 Accepted 23 November 2021

Check for updates

(C) Author(s) (or their employer(s)) 2021. Re-use permitted under CC BY-NC. No commercial re-use. See rights and permissions. Published by BMJ.

${ }^{1}$ Tianjin Union Medical Center, Tianjin Medical University,

Tianjin, China

${ }^{2}$ Department of Endocrinology, Health Management Center, Tianjin Union Medical Center, Nankai University-Affiliated Hospital, Tianjin, China

${ }^{3}$ School of Medicine, Nankai University, Tianjin, China

Correspondence to Dr Chunjun Li; li_chunjun@126.com and Jing-Na Lin;

13207628978@163.com

\section{ABSTRACT}

Objectives To explore the prevalence and risk factors of metabolic-associated fatty liver disease (MAFLD) in Tianjin government employees of different genders.

Design Cross-sectional study.

Setting Health Management Center of Tianjin Union Medical Center.

Participants 16924 government employees (59.6\% male).

Measures Ultrasound liver examination was performed to determine whether there is fat accumulation in the organ. Participants' weight and height were measured, and body mass index (BMI) was calculated.

Results The overall prevalence of MAFLD in this population was $40.76 \%$. The rates were significantly higher in men $(49.42 \%)$ than in women $(27.97 \%)$. The prevalence of MAFLD was highest in men aged 40-49 years (54.04\%) and women aged $60-69$ years $(43.44 \%)$. In all BMI groups, the prevalence was higher in men than that in women. In both genders, higher BMI was associated with the risk of MAFLD, especially for BMI $\geq 31.9 \mathrm{~kg} / \mathrm{m}^{2}$.

Conclusions The prevalence of MAFLD in government employees in Tianjin was significantly higher than the average level in China. The prevalence varied by sex and age group, and those with high BMI were at the highest risk of developing MAFLD.

\section{INTRODUCTION}

Metabolic-associated fatty liver disease (MAFLD), formerly named non-alcoholic fatty liver disease (NAFLD), is a series of progressive liver diseases ranging from steatosis, fatty liver disease, fibrosis, cirrhosis to hepatocellular carcinoma. ${ }^{12}$ Although many preliminary studies have found evidence that associates MAFLD with sedentary lifestyles, overnutrition and metabolic dysfunction, including type 2 diabetes mellitus (T2DM), dyslipidaemia, hypertension and obesity, ${ }^{2-4}$ its genesis is far from being completely clarified. ${ }^{5}$ Other experiments have already verified that gender differences also affect the prevalence of MAFLD. ${ }^{2}$ An International Consensus
Strengths and limitations of this study

- This was a large-scale study on the prevalence of metabolic-associated fatty liver disease (MAFLD) and its risk factors among Tianjin government employees.

- A limitation is that insulin resistance was assessed by the triglyceride-glucose index.

- Another limitation is that waist circumference, haemoglobin A1c and $\gamma$-glutamyl peptidase were not measured; only body mass index, fasting plasma glucose and alanine aminotransferase were measured.

- A further limitation is that participants' medication backgrounds were not collected and the severity of coronary heart disease was not considered.

Panel suggested that the nomenclature MAFLD more accurately reflects the current knowledge of fatty liver diseases associated with metabolic dysfunction, ${ }^{2}$ so the change from NAFLD to MAFLD helps identify individuals with a higher risk of liver or cardiovascular outcomes. ${ }^{67}$ More recent evidence reveals that Tianjin's abdominal obesity rate ranked first in China in both genders. ${ }^{8}$ This representative cross-sectional study of 174 840 Chinese adults suggested that the higher rates may be related to the breakfast options that are more popular in Tianjin: crispy rice, bean curd and pancake dumplings. A recent study by Pan et at showed that obesity is associated with the level of education in China. Among the male population, education level of male and obesity rates are directly proportional, but the opposite phenomenon is observed among the female population. ${ }^{9}$

The global prevalence of MAFLD is estimated to be $25.24 \% .{ }^{10}$ Considering the male population, the ranges vary between $4.3 \%$ and $42 \%$. The numbers change for the female population: the ranges go from $1.6 \%$ to $24 \%$ 
in different cohorts. ${ }^{11}$ The incidence of MAFLD extent from 19 to 44.5/1000 person-years in Asia, ${ }^{11}$ and the prevalence of this condition in China only reaches $29.2 \%{ }^{12}$ Moreover, because of the variant obesity rates and the different regional and economic development levels, the prevalence rates are constantly oscillating. ${ }^{11-13}$ In the past 20 years, due to China's rapid economic ascendance, the prevalence of MAFLD in coastal areas has significantly increased with the growth of per capita Gross National Product (GDP). ${ }^{14}$

Patients with simple steatosis are prone to develop more severe liver fibrosis and cirrhosis. Studies have found that some patients with this condition are also at risk of developing hepatocellular carcinoma. ${ }^{15} 16$ It has been demonstrated that cardiovascular diseases have become the major cause of death for patients with advanced MAFLD. ${ }^{17}$ Among patients with MAFLD, the risk of liverrelated morbidity and mortality is very high, and most of them are accompanied by metabolic complications. Those include obesity, dyslipidaemia, T2DM and metabolic syndrome, ${ }^{1618}$ which may put more pressure on the public health system and increase the economic burden to keep it functional.

Although the prevalence of MAFLD is high all over China, which directly affects its economic system, the high rates of MAFLD and obesity among Tianjin government employees have not yet been explained by any other phenomena. We have designed this cross-sectional study to clarify this issue in Tianjin and to explore the risk factors of MAFLD to provide a novel basis for relevant departments to plan effective preventive measures.

\section{METHODS}

\section{Participants}

A total of 18190 government employees from the Tianjin Union Medical Center-Health Management Center undergoing an annual health examination took part in this study from January 2020 to December 2020. Participants with incomplete physical examination data, such as height, weight, biochemical analysis and abdominal ultrasound, were excluded ( $\mathrm{n}=706)$. To avoid duplication of information, we only use the first physical examination data of participants who underwent multiple physical examinations throughout the year $(n=560)$. Finally, a total of 16924 participants with complete health examination data were included in the study, which accounted for $93.04 \%$ of the total (online supplemental figure 1).

\section{Patient and public involvement}

No patients were involved in setting the research question or the outcome measures, nor were they involved in the design and implementation of the study. There are no plans to involve patients in dissemination.

\section{Covariables}

Following the standard measurement method, all participants enrolled in this study were examined by a professional doctor for physical examination, with steps that included measuring height $(\mathrm{m})$, weight $(\mathrm{kg})$, blood pressure $(\mathrm{mm} \mathrm{Hg})$ and heart rate (subdegree/degree). It is noteworthy that height and weight were measured to an accuracy of 0.1. Body mass index (BMI) was calculated by dividing body weight $(\mathrm{kg})$ by the square of body height $\left(\mathrm{m}^{2}\right)$. Following the Chinese Obesity Standard, ${ }^{19}$ those with BMI $<18.5 \mathrm{~kg} / \mathrm{m}^{2}$ were considered lean, $18.5-23.9 \mathrm{~kg} / \mathrm{m}^{2}$ or $23.9-27.9 \mathrm{~kg} / \mathrm{m}^{2}$ were considered overweight, and individuals with BMI $\geq 27.9 \mathrm{~kg} / \mathrm{m}^{2}$ were considered obese. The group of participants with obesity was further divided into three categories: $27.9 \sim 31.9 \mathrm{~kg}$ / $\mathrm{m}^{2}, 31.9 \sim 35.9 \mathrm{~kg} / \mathrm{m}^{2}$ and $\geq 35.9 \mathrm{~kg} / \mathrm{m}^{2}$. After a 10 -minute rest in the seat, we used the electronic sphygmomanometer to measure the right upper arm blood pressure twice in a row. The interval between the two measurements was $1 \mathrm{~min}$ to reduce the measurement error. Systolic blood pressure greater than $140 \mathrm{~mm} \mathrm{Hg}$, and diastolic blood pressure greater than $90 \mathrm{~mm} \mathrm{Hg}$ or previously diagnosed as hypertension were considered higher than normal. After 8 hours of fasting overnight, venous blood was extracted for the examination of alanine aminotransferase (ALT), fasting plasma glucose (FPG), total cholesterol (TC), triglycerides (TG), low-density lipoprotein cholesterol (LDL-C), high-density lipoprotein cholesterol (HDL-C) and serum uric acid. Blood glucose greater than $6.1 \mathrm{mmol} / \mathrm{L}$ or previously diagnosed as diabetes was considered higher than normal. MAFLD was diagnosed according to the imaging evidence of fat accumulation in the liver, in addition to one of the three following criteria: the presence of T2DM, overweight/obesity, or evidence of metabolic dysregulation. ${ }^{20}$

\section{DATA ANALYSIS}

As the continuous variables were normally distributed by K-S normal test except for TG, the independent two-sample t-test or the Mann-Whitney $\mathrm{U}$ test was used to compare the continuous variables. The $\mathrm{X}^{2}$ test was performed using the categorical variables. A binary logistic regression analysis was performed to determine which factors were strongly related to MAFLD. All statistical analyses were conducted using SPSS V.25.0. The $p$ value less than 0.05 was considered significantly different. The $\mathrm{p}$ value was double tailed.

\section{RESULTS}

A total of 18190 government employees routinely undergoing an annual health examination took part in this study. Excluding those with incomplete physical examination data $(\mathrm{n}=706)$ and multiple physical examinations within 1 year $(n=560), 16924$ participants were finally recruited in the study (online supplemental figure 1). The clinical characteristics stratified by gender and MAFLD are displayed in table 1 . The overall prevalence of MAFLD was $40.76 \%$ ( $49.42 \%$ in men and $27.97 \%$ in women), and six participants were diagnosed with cirrhosis (men, $n=5)$. 


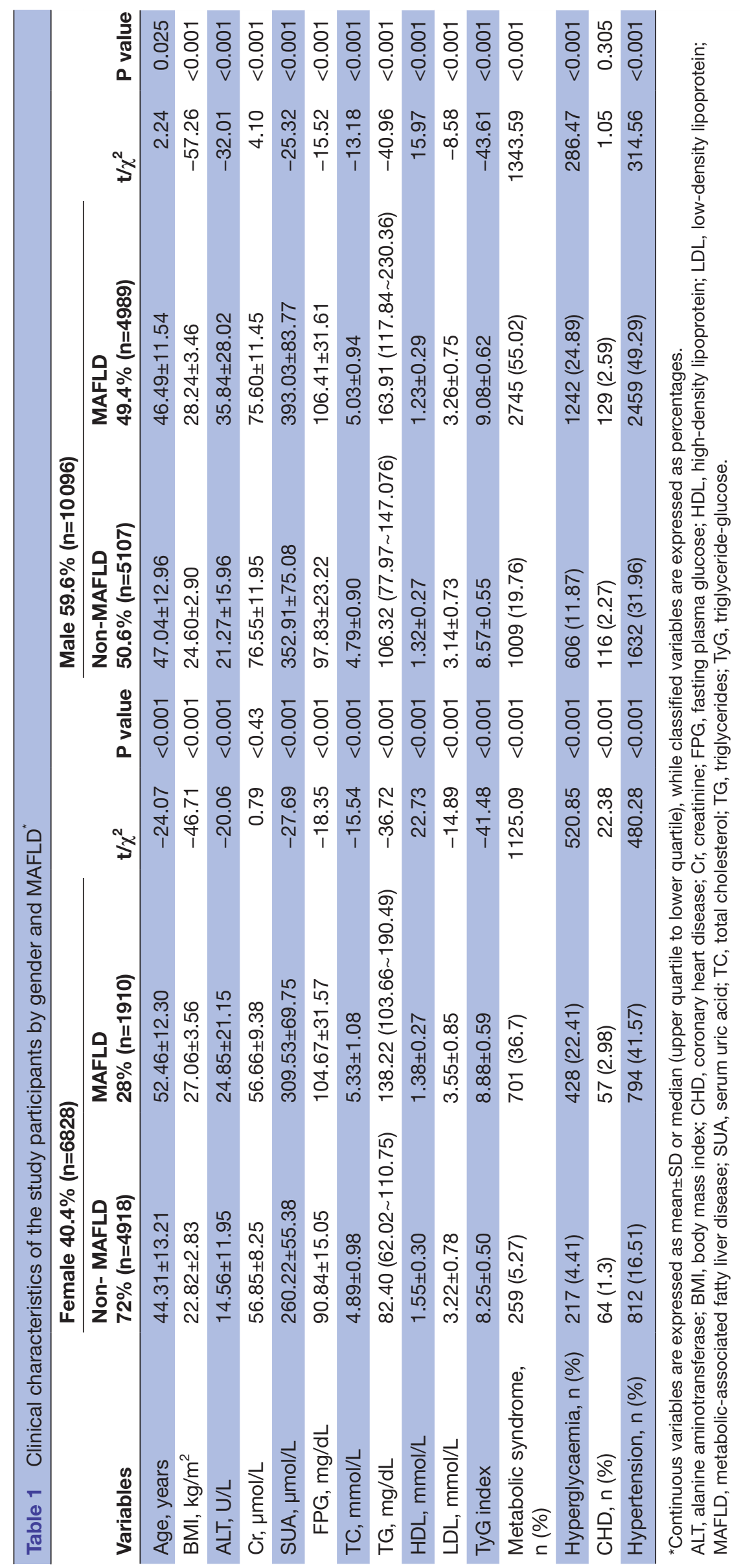




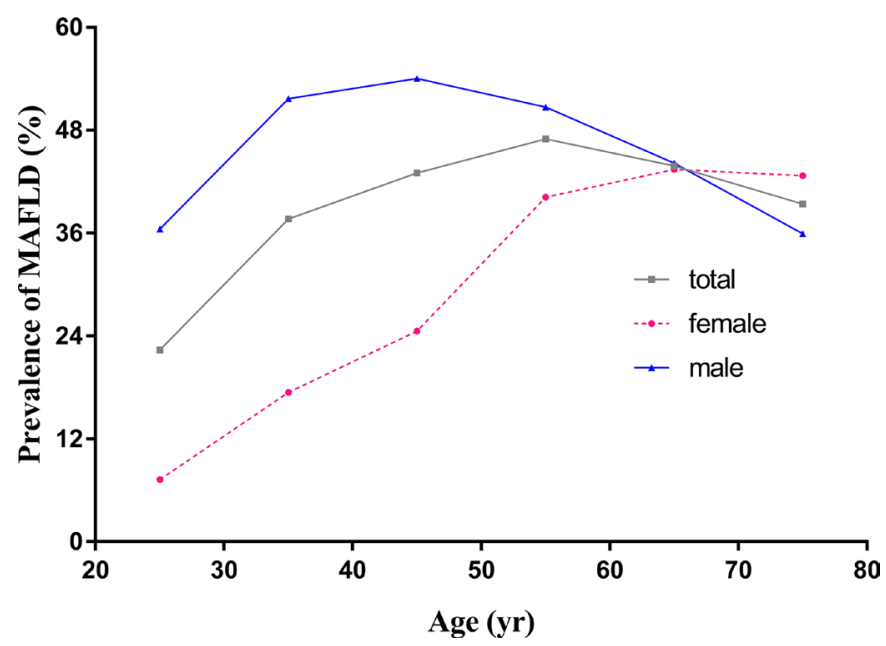

Figure 1 Prevalence of MAFLD in different age groups stratified by gender. MAFLD, metabolic-associated fatty liver disease.

The average age of men with MAFLD was 46.49 years old and the average age of women was 52.46 years old. The triglyceride-glucose (TyG) index of the MAFLD group was significantly higher than that of the non-MAFLD group, regardless of gender. In patients with MAFLD, $55.02 \%$ of men and $36.7 \%$ of women had more complicated conditions due to metabolic syndrome. A precise analysis of the differences between the MAFLD group and the nonMAFLD group showed that there were significant differences in all indicators of both genders, except for the prevalence of coronary heart disease (CHD).

To better understand the influence of different age groups on the prevalence of MAFLD, we further divided the participants by age, as shown in figure 1 . After stratification by age, the prevalence of MAFLD among men was significantly higher than that among women before the age group of 50-59 years $(p<0.001)$. However, there was no significant difference in the prevalence of MAFLD in both gender groups aged $60-69$ years $(\mathrm{p}=0.715)$ and aged 70 years or older $(p=0.072)$. In the male group, the highest prevalence rate was found in the group of people from 40 to 49 years old (54.04\%). We have noticed that this rate gradually decreased with age, especially after 50 years old. The lowest prevalence rate of $35.95 \%$ was found in the group of participants over 70 years old (refer to figure 1). Interestingly, in the female group, the lowest prevalence was $7.27 \%$ in the group formed by those who were younger than 29 years old, and the highest rate$43.44 \%$-was observed in the group aged 60-69 years old, but it slightly decreased after 70 years old. However, in the general population, the prevalence gradually increased with age, more specifically before $50-59$ years old. This group reached a peak of $47 \%$, and then the rates started to gradually decrease with age.

The overweight and obesity rate of male Tianjin government employees was higher than that of female-44.5\% and $30.4 \%$, respectively (figure 2). Additionally, differences in the prevalence of MAFLD across gender groups

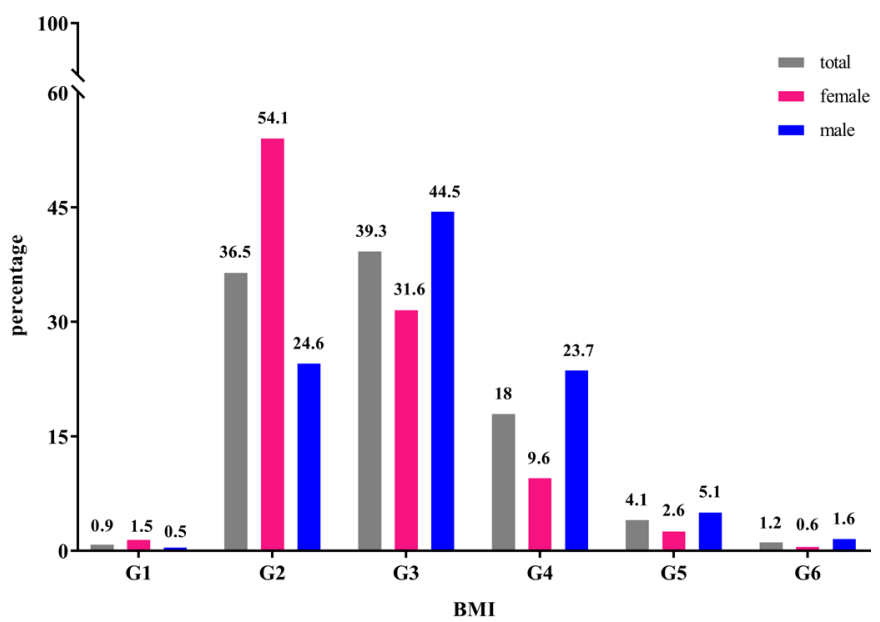

Fig 2. percentage of different BMI groups in females and males

Figure 2 Percentage of different BMI groups in women and men/BMl groups, G1: <18.5, G2: 18.5 23.9, G3: 23.9 27.9, G4: 27.9 31.9, G5: 31.9 35.9, G6: $\geq 35.9$. BMI, body mass index.

increased proportionally with BMI (figure 3). Men had a significantly higher prevalence of MAFLD than women at any given BMI. So, we have concluded that MAFLD was positively associated with the levels of BMI in all the participants, regardless of gender.

The association between BMI, age and MAFLD is exhibited in figure 4. After adjusting for ALT, TC, HDL-C, LDL-C, uric acid, TyG index and history of diseases, the risk of MAFLD kept rising as BMI increased. Especially when BMI $\geq 31.9 \mathrm{~kg} / \mathrm{m}^{2}$, the risk increased significantly for both men and women. With BMI $<31.9 \mathrm{~kg} / \mathrm{m}^{2}$, the risk of MAFLD in women was slightly higher than that in men, but it is worth noting that when BMI $\geq 31.9 \mathrm{~kg} / \mathrm{m}^{2}$, the risk of MAFLD in men $\left(31.9 \mathrm{~kg} / \mathrm{m}^{2} \leq \mathrm{BMI}<35.9 \mathrm{~kg} / \mathrm{m}^{2}\right.$, OR 17.47; $95 \%$ CI 12.64 to $24.14 ; \mathrm{p}<0.001 ; \mathrm{BMI} \geq 35.9 \mathrm{~kg} / \mathrm{m}^{2}$, OR $23.4 ; 95 \%$ CI 11.85 to $46.21 ; \mathrm{p}<0.001$ ) was significantly higher than that in women $\left(31.9 \mathrm{~kg} / \mathrm{m}^{2} \leq \mathrm{BMI}<35.9 \mathrm{~kg} /\right.$

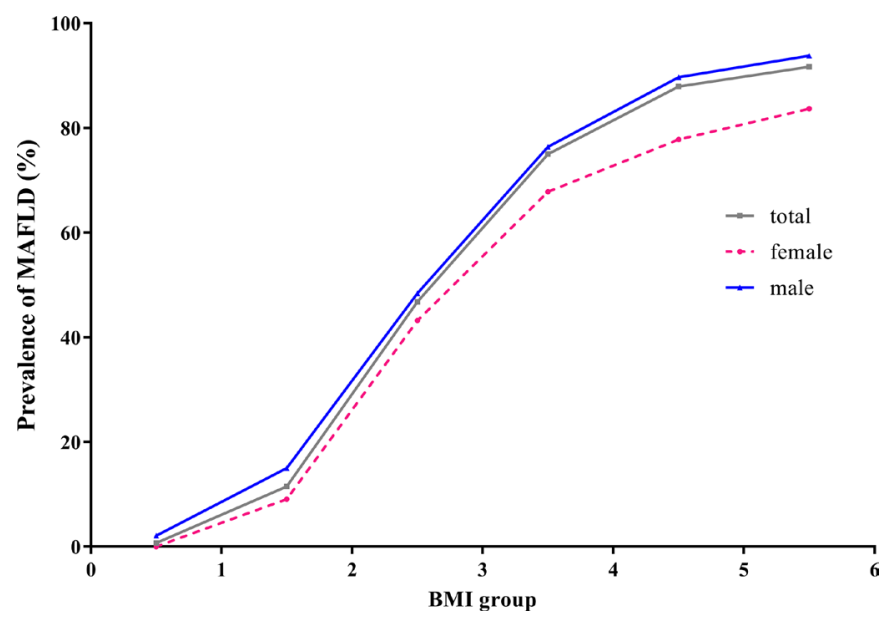

Figure 3 Prevalence of MAFLD in BMI groups stratified by gender/BMI groups, G1: <18.5, G2: 18.5 23.9, G3: 23.9 27.9, G4: 27.9 31.9, G5: 31.9 35.9, G6: $\geq 35.9$. BMI, body mass index; MAFLD, metabolic-associated fatty liver disease. 

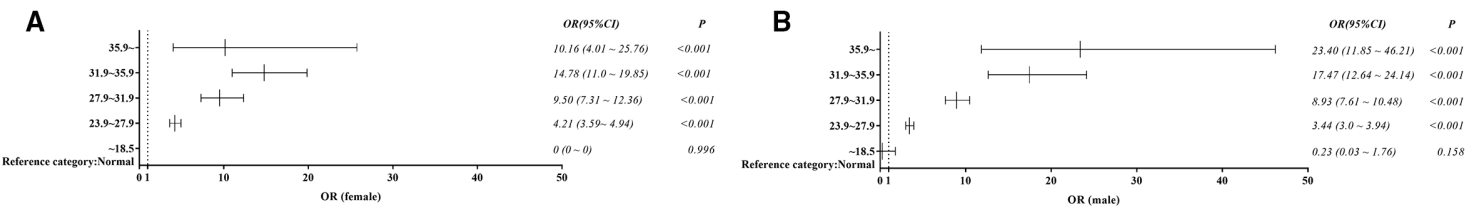

C

D
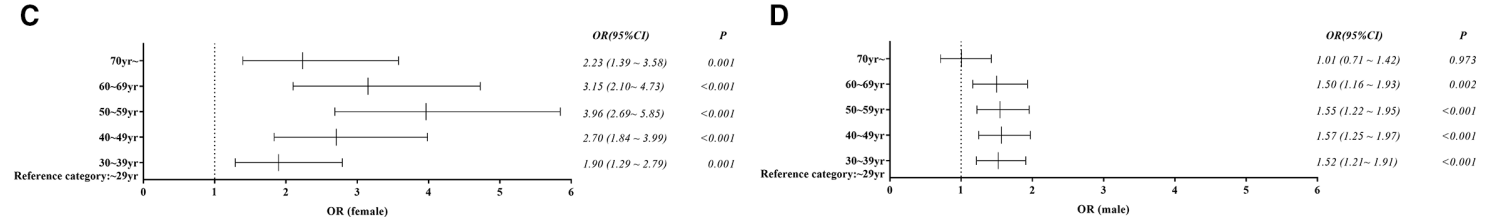

Figure 4 Forest map for binary logistic regression analysis of women and men. (A) OR for the association between body mass index (BMI) and MAFLD of women. (B) OR for the association between BMI and MAFLD of men. (C) OR for the association between age and MAFLD of women. (D) OR for the association between age and MAFLD of men. MAFLD, metabolic-associated fatty liver disease.

$\mathrm{m}^{2}$, OR $14.78 ; 95 \%$ CI 11.0 to $19.85 ; \mathrm{p}<0.001 ; \mathrm{BMI}$ $\geq 35.9 \mathrm{~kg} / \mathrm{m}^{2}$, OR $10.16 ; 95 \%$ CI 4.01 to $\left.25.76 ; \mathrm{p}<0.001\right)$. The highest risk of MAFLD among women was among the group of individuals from 50 to 59 years old (OR 3.96; $95 \%$ CI 2.69 to 5.85), while the risk among men tends to be the same in all age groups except for those over 70 years old.

\section{DISCUSSION}

In the current study, we found that the prevalence of MAFLD among government employees who underwent annual health examination in the Health Management and Examination Center of Tianjin People's Hospital in 2020 was $40.76 \%$. Considering two different gender groups, we have confirmed that the prevalence for men was $49.42 \%$ and that for women was $27.97 \%$. The difference is considerable and should make people highly vigilant about this issue. Furthermore, we analysed its risk factors and found that BMI $\geq 31.9 \mathrm{~kg} / \mathrm{m}^{2}$ and women aged between 50 and 59 years old had the highest risk of developing MAFLD compared with those younger than 29 years old.

This is the first large-scale cross-sectional study that explores the prevalence of MAFLD and its related risk factors among government employees in Tianjin. MAFLD is closely related to metabolic disorders, especially obesity. More recent evidence highlights that the prevalence of abdominal obesity in Tianjin ranks first in China regardless of gender, ${ }^{8}$ which may partly explain the high prevalence of MAFLD among government employees in Tianjin. The typical breakfast option in that region includes rice crust, bean curd and pancake fruit, all high-fat options that might lead to obesity. Currently, the prevalence of MAFLD in China is $29.2 \%$ and it keeps rising at an alarming rate with changes in people's lifestyles and the rapid development of the national economy, especially in economically developed regions. ${ }^{12}$ A systematic review by Zhu et $a l^{14}$ on the relationship between China's economy and the prevalence of MAFLD found that the number of MAFLD cases had rapidly increased with economic development in the past few decades, especially in coastal areas. Scholars have researched other areas of the country and found that prevalence of MAFLD among employees in Taipei, Taiwan is $48.4 \%,{ }^{21}$ that in Shanghai is $38.17 \%^{22}$ and that in Hong Kong is $42 \%,{ }^{23}$ all higher than that in Chengdu, an inland city, where the prevalence rate is only $12.5 \% .^{24}$ Tianjin is an independently administered municipal district and is also a coastal region with a well-developed economy, which may be one reason for the high prevalence of MAFLD in that area. In addition, another reason for this phenomenon may be that our research subjects are government employees, who usually have a sedentary lifestyle and lack a healthy routine of exercises, which are factors associated with MAFLD. Williams et $a l^{25}$ conducted a prospective study on the prevalence of MAFLD among 400 middle-aged people, showing that people who develop this condition are those who often eat fast food and exercise less. Therefore, the high prevalence of MAFLD among government employees in Tianjin is worth paying attention to.

We analysed the distribution of the prevalence of MAFLD in men and women at different ages. Among men, the rate reached its peak among those from 40 to 49 years old. Among women, the highest rate was found in the group of individuals from 60 to 69 years old. The prevalence of this condition among men was significantly higher than that among women before the age of 50-59 years. Interestingly, women aged 50-59 years have the highest risk of MAFLD, while men have no significant difference in risk among different age groups, except those aged over 70 years. The outcomes of our research indicate that young and middle-aged men and postmenopausal women are high-risk groups for MAFLD. Many studies in China and abroad have previously emphasised that age is closely related to the occurrence and development of MAFLD. ${ }^{26}$ A study conducted in China Health Big Data (China Biobank) Project has shown that waist circumference and visceral fat area increase with age ${ }^{28}$ so, from a long-term perspective, it is necessary to pay attention to young and middle-aged men to prevent or reverse the progress of MAFLD. Similar to part of our research results, a study conducted by Fung et $a l^{23}$ pointed out that 
significant gender differences affected the MAFLD rates among the young and middle-aged population. However, the study did not analyse whether gender also impacts the rates among the elderly population (over 70 years old), which is essential for women of this age group to attach importance to the prevention of MAFLD. Previous studies have shown that oestrogen is a protective factor for MAFLD in premenopausal women,${ }^{23}{ }^{29}$ which explains our results. We have found that the prevalence of MAFLD in postmenopausal women has soared, since the level of oestrogen decreases at this stage. Women from 50 to 59 years old are part of the risk group and the highest occurrence rate was found among them. In this case, changing the lifestyle-which may include moderate physical activity and a balanced diet-is important for young and middle-aged men and postmenopausal women and can help to reduce the high prevalence of MAFLD, prevent and eventually reverse the progress of the disease.

In our study, we found that the prevalence of MAFLD was positively associated with BMI, and the prevalence in men was higher than in women. The overweight rate and obesity rate of men were $44.5 \%$ and $30.4 \%$, respectively, and were higher than that of women. Through binary logistic regression analysis, we have concluded that overweight and obesity were the primary risk factors for MAFLD in both genders. When BMI $\geq 31.9 \mathrm{~kg} / \mathrm{m}^{2}$, the risk of male MAFLD was significantly higher than in women, indicating that obese men should pay more attention to weight management and prevention of MAFLD. Similar to our findings, a study from Pan et at showed that the obesity rate of men was positively correlated with education level, while the obesity rate of women showed an opposite trend. A recent study conducted by Sarkar $e t a l^{30}$ showed that reduced testosterone levels in obese men independently associated with fatty liver may partially explain this phenomenon, but further analysis is necessary to accurately understand these mechanisms. Although our recent review of the literature on this topic suggests that the obesity index is not at all associated with the prevalence rate of MAFLD, some preliminary studies consistent with our research results have pointed out that overweight and obesity are independent risk factors for MAFLD ${ }^{3132}$ Other scholars have also associated the rising obesity rate with the simultaneous rise in the prevalence of MAFLD. ${ }^{18} 3334$ However, a growing body of literature has pointed out that weight loss can prevent MAFLD from progressing to more serious fatty hepatitis and liver cirrhosis, or even completely reverse the condition, ${ }^{35-37}$ which has attracted our attention. Combining our outcomes with the results of the aforementioned studies, we have concluded that new strategies are necessary to effectively curb the further spread of MAFLD. A healthy routine of exercises and a balanced diet are methods that can help to control the increasing incidence rate of this condition and may help reduce the existing prevalence rate, especially in Tianjin, where a significant part of the population is obese.

This is the first large-scale study on the prevalence of MAFLD and its risk factors among Tianjin government employees. All measurements and statistical analyses were performed in strict accordance with the standard procedures to ensure data accuracy. However, the limitations of our study should also be addressed. First, we did not use the homeostatic model assessment of insulin resistance (HOMA-IR), surrogated with the TyG index easily applicated in routine physical check-up. Recent studies have shown that TyG index can replace HOMA-IR to evaluate insulin resistance, ${ }^{38}$ and its evaluation effect is even stronger than HOMA-IR. ${ }^{39}$ Second, we did not include all the risk factors, such as waist circumference, haemoglobin A1c and $\gamma$-glutamyl peptidase which were not measured during the routine physical check-up, but we measured BMI, FPG and ALT. Finally, we did not collect the participants' medication information and the severity classification of CHD, which may cause slight bias to the basic understanding of the conditions of patients with MAFLD.

\section{CONCLUSIONS}

MAFLD is a very common condition among the group of Tianjin government employees, especially in postmenopausal women and obese men and men aged 40-49 years. Overweight or postmenopausal women and obese men or men aged 40-49 years should consider changing their lifestyles which include moderate physical activities and a balanced diet to their daily routine in order to improve their conditions. These changes may help to formulate personalised prevention and treatment strategies for the occurrence and progress of MAFLD in high-risk groups.

Acknowledgements We are very grateful to all the participants in this study and all the employees of Tianjin Union Medical Center-Health Management Center for their great help in this study.

Contributors C-J L and J-N L contributed to the concept, supervising and design of the study . Y-P H, S Zh and M-Y Zh contributed to the design of the analysis, data analysis and manuscript preparation; $\mathrm{Y}-\mathrm{P} \mathrm{H}, \mathrm{Y} \mathrm{W}, \mathrm{W}-\mathrm{H} \mathrm{W}$ and $\mathrm{J} \mathrm{L}$ contributed to the coordination of the work, data collection and management, and interpretation of results and revision of manuscript drafts. All authors have approved the final article.

Funding This work was supported by the grant from the Natural Science Foundation of Tianjin (19JCZDJC36100 to C-J L).

Competing interests None declared.

Patient consent for publication Not required.

Ethics approval This study involves human participants and was approved by the Institutional Review Board of Tianjin Union Medical Center (No. 2021C06). Participants gave informed consent to participate in the study before taking part.

Provenance and peer review Not commissioned; externally peer reviewed. Data availability statement Data are available upon reasonable request.

Supplemental material This content has been supplied by the author(s). It has not been vetted by BMJ Publishing Group Limited (BMJ) and may not have been peer-reviewed. Any opinions or recommendations discussed are solely those of the author(s) and are not endorsed by BMJ. BMJ disclaims all liability and responsibility arising from any reliance placed on the content. Where the content includes any translated material, BMJ does not warrant the accuracy and reliability of the translations (including but not limited to local regulations, clinical guidelines, terminology, drug names and drug dosages), and is not responsible for any error and/or omissions arising from translation and adaptation or otherwise.

Open access This is an open access article distributed in accordance with the Creative Commons Attribution Non Commercial (CC BY-NC 4.0) license, which permits others to distribute, remix, adapt, build upon this work non-commercially, and license their derivative works on different terms, provided the original work is 
properly cited, appropriate credit is given, any changes made indicated, and the use is non-commercial. See: http://creativecommons.org/licenses/by-nc/4.0/.

\section{ORCID iD}

Chunjun Li http://orcid.org/0000-0003-4857-8146

\section{REFERENCES}

1 Anstee QM, Targher G, Day CP. Progression of NAFLD to diabetes mellitus, cardiovascular disease or cirrhosis. Nat Rev Gastroenterol Hepatol 2013;10:330-44.

2 Eslam M, Sanyal AJ, George J, et al. MAFLD: a consensus-driven proposed nomenclature for metabolic associated fatty liver disease. Gastroenterology 2020;158:1999-2014.

3 Younossi ZM, Golabi P, de Avila L, et al. The global epidemiology of NAFLD and NASH in patients with type 2 diabetes: a systematic review and meta-analysis. J Hepatol 2019;71:793-801.

4 Lee HW, Wong GL-H, Kwok R, et al. Serial transient elastography examinations to monitor patients with type 2 diabetes: a prospective cohort study. Hepatology 2020;72:1230-41.

5 Tarantino G, Citro V, Capone D. Nonalcoholic fatty liver disease: a challenge from mechanisms to therapy. J Clin Med 2019;9:15. doi:10.3390/jcm9010015

6 Lee H, Lee Y-H, Kim SU, et al. Metabolic dysfunction-associated fatty liver disease and incident cardiovascular disease risk: a nationwide cohort study. Clin Gastroenterol Hepatol 2021;19:2138-47.

7 Wong VW-S, Wong GL-H, Woo J, et al. Impact of the new definition of metabolic associated fatty liver disease on the epidemiology of the disease. Clin Gastroenterol Hepatol 2021;19:2161-71.

8 Zhang X, Zhang M, Zhao Z, et al. Geographic variation in prevalence of adult obesity in China: results from the 2013-2014 national chronic disease and risk factor surveillance. Ann Intern Med 2020;172:291-3.

9 Pan X-F, Wang L, Pan A. Epidemiology and determinants of obesity in China. Lancet Diabetes Endocrinol 2021;9:373-92.

10 Younossi ZM, Koenig AB, Abdelatif D, et al. Global epidemiology of nonalcoholic fatty liver disease-Meta-analytic assessment of prevalence, incidence, and outcomes. Hepatology 2016;64:73-84.

11 Burra P, Bizzaro D, Gonta A, et al. Clinical impact of sexual dimorphism in non-alcoholic fatty liver disease (NAFLD) and nonalcoholic steatohepatitis (NASH). Liver Int 2021;41:1713-33.

12 Zhou F, Zhou J, Wang W, et al. Unexpected rapid increase in the burden of NAFLD in China from 2008 to 2018: a systematic review and meta-analysis. Hepatology 2019;70:1119-33.

13 Zhu J-Z, Dai Y-N, Wang Y-M, et al. Prevalence of nonalcoholic fatty liver disease and economy. Dig Dis Sci 2015;60:3194-202.

14 Zhu J-Z, Zhou Q-Y, Wang Y-M, et al. Prevalence of fatty liver disease and the economy in China: a systematic review. World J Gastroenterol 2015;21:5695-706.

15 Ascha MS, Hanouneh IA, Lopez R, et al. The incidence and risk factors of hepatocellular carcinoma in patients with nonalcoholic steatohepatitis. Hepatology 2010;51:1972-8.

16 Perumpail BJ, Khan MA, Yoo ER, et al. Clinical epidemiology and disease burden of nonalcoholic fatty liver disease. World $\mathrm{J}$ Gastroenterol 2017;23:8263-76.

17 Targher G, Day CP, Bonora E. Risk of cardiovascular disease in patients with nonalcoholic fatty liver disease. $N$ Engl J Med 2010;363:1341-50.

18 Younossi Z, Anstee QM, Marietti M, et al. Global burden of NAFLD and NASH: trends, predictions, risk factors and prevention. Nat Rev Gastroenterol Hepatol 2018;15:11-20.

19 Zhou B-F, Cooperative Meta-Analysis Group of the Working Group on Obesity in China. Predictive values of body mass index and waist circumference for risk factors of certain related diseases in Chinese adults--study on optimal cut-off points of body mass index and waist circumference in Chinese adults. Biomed Environ Sci 2002;15:83-96.

20 Eslam M, Newsome PN, Sarin SK, et al. A new definition for metabolic dysfunction-associated fatty liver disease: an international expert consensus statement. J Hepatol 2020;73:202-9.

21 Wang J, Chiu W-H, Chen R-C, et al. The clinical investigation of disparity of nonalcoholic fatty liver disease in a Chinese occupational population in Taipei, Taiwan: experience at a teaching hospital. Asia Pac J Public Health 2015;27:NP1793-804.

$22 \mathrm{Hu} \mathrm{X}$, Huang Y, Bao Z, et al. Prevalence and factors associated with nonalcoholic fatty liver disease in Shanghai work-units. BMC Gastroenterol 2012;12:123.

23 Fung J, Lee C-K, Chan M, et al. High prevalence of non-alcoholic fatty liver disease in the Chinese - results from the Hong Kong liver health census. Liver Int 2015;35:542-9.

24 Li H, Wang Y-J, Tan K, et al. Prevalence and risk factors of fatty liver disease in Chengdu, Southwest China. Hepatobiliary Pancreat Dis Int 2009;8:377-82.

25 Williams CD, Stengel J, Asike MI, et al. Prevalence of nonalcoholic fatty liver disease and nonalcoholic steatohepatitis among a largely middle-aged population utilizing ultrasound and liver biopsy: a prospective study. Gastroenterology 2011;140:124-31.

26 Shima T, Seki K, Umemura A, et al. Influence of lifestyle-related diseases and age on the development and progression of nonalcoholic fatty liver disease. Hepatol Res 2015;45:548-59.

27 Cai M-J, Kong X-N, Zhao X-Y. Influences of gender and age on the prevalence and complications of nonalcoholic fatty liver disease. Zhongguo Yi Xue Ke Xue Yuan Xue Bao 2017;39:499-505.

28 Zeng Q, Wang L, Dong S, et al. CT-derived abdominal adiposity: distributions and better predictive ability than BMI in a nationwide study of 59,429 adults in China. Metabolism 2021;115:154456.

29 Lonardo A, Nascimbeni F, Ballestri S, et al. Sex differences in nonalcoholic fatty liver disease: state of the art and identification of research gaps. Hepatology 2019;70:1457-69.

30 Sarkar M, Yates K, Suzuki A, et al. Low testosterone is associated with nonalcoholic steatohepatitis and fibrosis severity in men. Clin Gastroenterol Hepatol 2021;19:400-2.

31 Musso G, Gambino R, Cassader M, et al. Meta-Analysis: natural history of non-alcoholic fatty liver disease (NAFLD) and diagnostic accuracy of non-invasive tests for liver disease severity. Ann Med 2011;43:617-49.

32 Bellentani S. The epidemiology of non-alcoholic fatty liver disease. Liver Int 2017;37 Suppl 1:81-4.

33 Vernon G, Baranova A, Younossi ZM. Systematic review: the epidemiology and natural history of non-alcoholic fatty liver disease and non-alcoholic steatohepatitis in adults. Aliment Pharmacol Ther 2011;34:274-85.

34 Fan J-G, Farrell GC. Epidemiology of non-alcoholic fatty liver disease in China. J Hepatol 2009;50:204-10.

35 Weiß J, Rau M, Geier A. Non-Alcoholic fatty liver disease: epidemiology, clinical course, investigation, and treatment. Dtsch Arztebl Int 2014;111:447-52.

36 Romero-Gómez M, Zelber-Sagi S, Trenell M. Treatment of NAFLD with diet, physical activity and exercise. J Hepatol 2017;67:829-46.

37 Do A, Kuszewski EJ, Langberg KA, et al. Incorporating weight loss medications into hepatology practice for nonalcoholic steatohepatitis. Hepatology 2019;70:1443-56.

38 Sánchez-García A, Rodríguez-Gutiérrez R, Mancillas-Adame L, et al. Diagnostic accuracy of the triglyceride and glucose index for insulin resistance: a systematic review. Int J Endocrinol 2020;2020:1-7.

39 Park HM, Lee HS, Lee Y-J, et al. The triglyceride-glucose index is a more powerful surrogate marker for predicting the prevalence and incidence of type 2 diabetes mellitus than the homeostatic model assessment of insulin resistance. Diabetes Res Clin Pract 2021;180:109042. 